\title{
Influence of the Pecking Motion Frequency on the Cyclic Fatigue Resistance of Endodontic Rotary Files
}

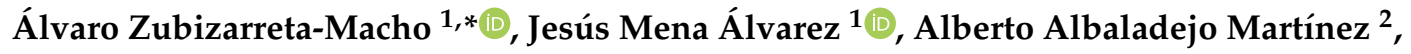 \\ Juan José Segura-Egea ${ }^{3}{ }^{(0)}$, Javier Caviedes Brucheli $\left.{ }^{4}{ }^{(}\right)$, Rubén Agustín-Panadero ${ }^{5}{ }^{(D}$, \\ Roberto López Píriz ${ }^{6}$ and Óscar Alonso-Ezpeleta ${ }^{7}$ 미 \\ 1 Department of Endodontics, Faculty of Health Sciences, Alfonso X el Sabio University, 28691 Madrid, Spain; \\ jmenaalvarez@gmail.com \\ 2 Department of Dentistry, School of Medicine, University of Salamanca, 37008 Salamanca, Spain; \\ albertoalbaladejo@hotmail.com \\ 3 Faculty of Dentistry, University of Sevilla, C/Avicena s/n, 41009 Sevilla, Spain; segurajj@us.es \\ 4 Centro de Investigaciones Odontológicas (CIO) Pontificia, Universidad Javeriana, Bogotá 1101, Colombia; \\ javiercaviedes@gmail.com \\ 5 Department of Stomatology, Faculty of Medicine and Dentistry, University of Valencia, 46010 Valencia, Spain; \\ rubenagustinpanadero@gmail.com \\ 6 Institute of Materials Science of Madrid, Superior Council of Scientific Investigations, 28222 Madrid, Spain; \\ lopezpiriz@gmail.com \\ 7 Department of Endodontics, School of Health Sciences, University of Zaragoza, 22006 Aragorn, Spain; \\ lalonezp@unizar.es \\ * Correspondence: amacho@uax.es
}

Received: 2 November 2019; Accepted: 20 December 2019; Published: 24 December 2019

\begin{abstract}
Purpose: To analyze the influence of the pecking motion frequency on the cyclic fatigue resistance of endodontic rotary files. Material and Methods: Sixty PlexV 25.06 endodontic rotary files were selected and distributed into three groups: 30 movements/min $(n=20), 60$ movements $/ \mathrm{min}$ $(n=20)$, and 120 movements/min $(n=20)$. A dynamic cyclic fatigue device was designed using Computer Aided Design/ Computer Aided Engineering (CAD/CAE) technology and manufactured by $3 \mathrm{D}$ impressions to simulate the pecking motion performed by an operator. Failures of the endodontic rotary files were detected by a Light-Emitting Diode (LED)/Light-Dependent Resistor (LDR) system controlled by an Arduino-Driver complex and management software. Endodontic rotary files were tested on an artificial root canal manufactured by wire electrical discharge machining $(\mathrm{EDM})$, with similar dimensions to those of the instrument under examination. Endodontic rotary files were used following the manufacturer's recommendations. The results were analyzed by ANOVA and Weibull statistics. Results: All pairwise comparisons revealed statistically significant differences in all three variables, except for the difference in the number of cycles between the groups with 60 and 120 movements/min $(p=0.298)$. The scale distribution parameter of Weibull statistics showed statistically significant differences in all three variables, except for the differences in the number of cycles between groups with 30 and 60 movements/min $(p=0.0722)$. No statistically significant differences in the three variables were observed for the shape distribution parameter. Conclusion: A low frequency of pecking motion is recommended to reduce the risk of failure of endodontic rotary files associated with cyclic fatigue.
\end{abstract}

Keywords: endodontics; cyclic fatigue; pecking motion; endodontic rotary files; NiTi rotary files 


\section{Introduction}

Endodontic rotary files have experienced continuous development since nickel-titanium (NiTi) files were introduced in the 1980s [1]. This alloy increases the flexibility and strength of rotary files compared with stainless-steel instruments [2], and it simplifies the endodontic procedure by improving the speed, accuracy, and safety of root canal shaping [3]. Despite continuous enhancements in the design and manufacture of NiTi rotary files to reduce the occurrence of failure during root canal shaping [4], failures can still occur. Many variables can contribute to file separation, but the main causes are cyclic bending fatigue and torsional overload [5-8]. Torsional overload is caused by the blockage of the endodontic files during rotational movement [9]. However, NiTi instrument failures are primarily caused by cyclic fatigue, which occurs when a NiTi endodontic instrument rotates in a curved root canal [10]. During rotation, the structure of the endodontic instrument is alternately subjected to compressive and tensile stress cycles, which produce microstructural changes that lead to the failure of the endodontic rotary file [11]. Root canal shape, instrument geometry, rotational speed, torque, instrument surface treatments, sterilization cycles, the number of clinical uses, and the chemical composition of NiTi alloys are the main factors that affect the number of cycles to failure (NCF) of NiTi rotary instruments $[12,13]$. However, the influence of the pecking motion (frequency of in-and-out movement) on the cyclic fatigue resistance of endodontic rotary instruments has never been tested. In 2002, the American National Standard Institute and the American Dental Association standardized a protocol for testing the torsional and flexibility resistance of stainless-steel manual files [14], which was also addressed in the 3630-1 norm by the International Organization for Standardization (ISO) [15] for endodontic instruments with a taper of $2 \%$. However, there is no international standard for testing the cyclic fatigue behavior of NiTi endodontic rotary instruments [11], and several self-designed devices and methods have been used [11]. However, none of these custom-made devices have been capable of dynamically testing the cyclic fatigue of NiTi endodontic rotary instruments in vitro with an automatic detection system and an anatomically based artificial root canal.

The aim of this work was to analyze the influence of the pecking motion on the cyclic fatigue resistance of endodontic rotary instruments; the null hypothesis (H0) asserts that the frequency of the pecking motion does not significantly affect the time to failure, the NCF, or the cyclic fatigue resistance of endodontic rotary instruments.

\section{Materials and Methods}

\subsection{Study Design}

Sixty sterile NiTi CM Wire endodontic rotary instruments 25.06 (Plex V2 ${ }^{\circledR}$, Orodeka, Italia) were involved in this study. Before the experiment, every endodontic rotary instrument was inspected for defects or deformities under a stereomicroscope (SZR-10, Optika, Bergamo, Italy), and none were discarded. A randomized controlled experimental trial was performed at the Dental Centre of Innovation and Advanced Specialties at the Alfonso X el Sabio University (Madrid, Spain) between February and July 2019. The endodontic rotary instruments were randomized (Epidat 4.1, Galicia, Spain) and distributed into the three groups: (A) 30 pecking movements/min $(n=20)$, (B) 60 pecking movements/min $(n=20)$, and (C) 120 pecking movements/min $(n=20)$.

\subsection{The Experimental Cyclic Fatigue Model}

The cyclic fatigue tests were performed using a custom-made device (Utility Model Patent number ES1219520) that provides information about the behavior of an endodontic rotary file during a root canal treatment. The endodontic rotary instruments were neither used nor submitted to sterilization cycles before the tests. The structure was designed by 2D/3D Computer-Aided Design/Computer-Aided Engineering (CAD/CAE) (Midas FX+ ${ }^{\circledR}$, Brunleys, MK, UK) and manufactured by 3D impression (ProJet ${ }^{\circledR}$ 6000. 3D Systems $@$, Rock Hill, SC, USA) (Figure 1). 

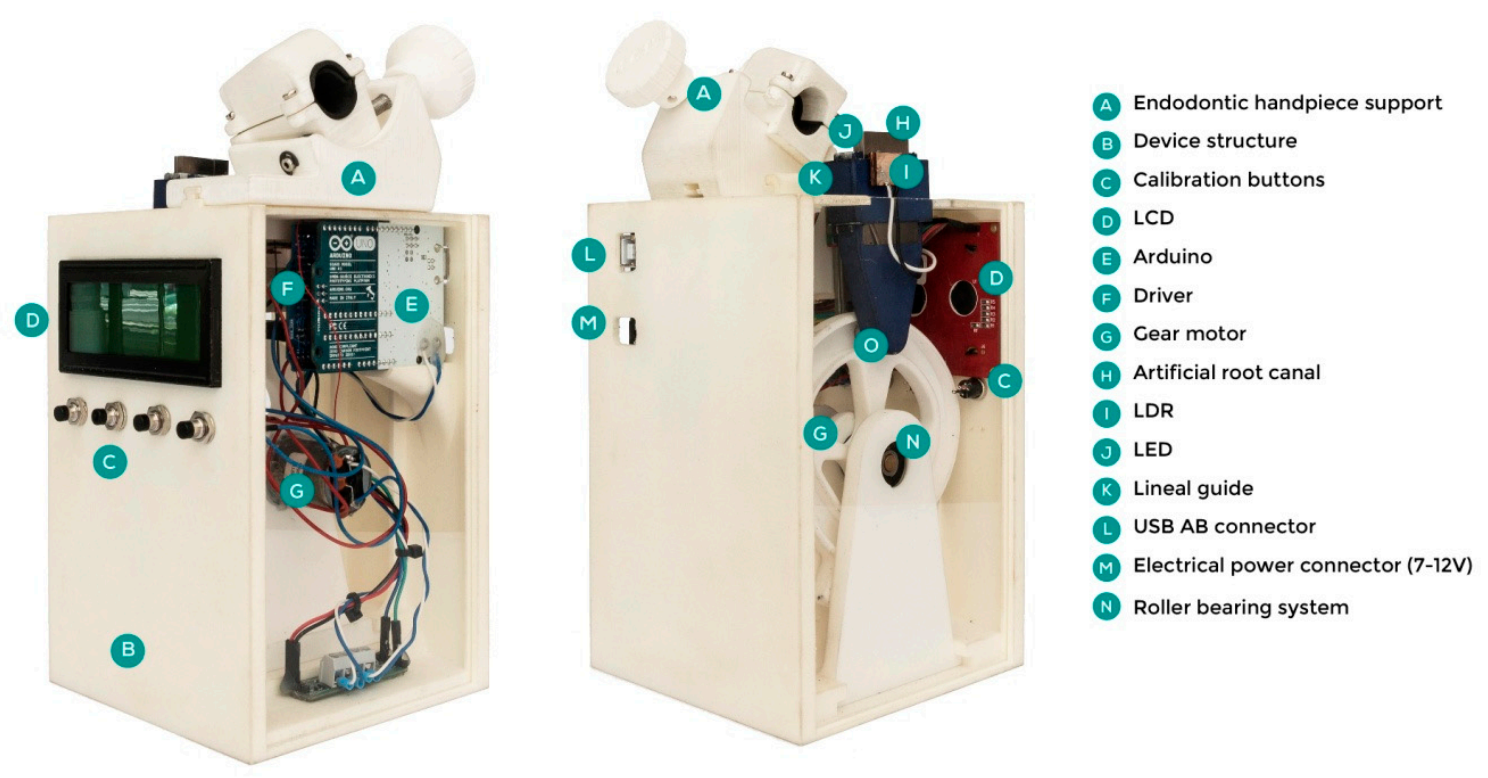

Figure 1. Parts of the hardware of the cyclic fatigue test device.

The endodontic handpiece (X-Smart Plus, Dentsply Maillefer, Baillagues, Switzerland) was scanned (3D Geomagic Capture Wrap, 3D Systems@), Rock Hill, SC, USA) to create an accurate design for its support piece by means of inverse engineering technology (Midas FX+ ${ }^{\circledR}$, Brunleys) and 3D impression manufacture (ProJet ${ }^{\circledR}$ 6000. 3D Systems $@$, Rock Hill, SC, USA). This support was firmly attached to the main structure and enabled the angular displacement of the endodontic handpiece by means of a spindle to test different file lengths. The support also allowed the files to be removed during the cyclic fatigue tests.

The direction and speed of the movement were produced by the brushed DC gearmotor (Ref.: 1589, Pololu ${ }^{\circledR}$ Corporation, Las Vegas, NV, USA) controlled by the driver (Ref.: DRV8835, Pololu ${ }^{\circledR}$ Corporation, Las Vegas, NV, USA), which performed an H-bridge function that controlled the speed movement through Pulse Width Modulation (PWM) signals emitted by four switches modulated by transistors. The movement was transferred to the artificial root canal support through a roller bearing system (Ref.: MR104ZZ, FAG, Schaeffler Herzogenaurach, Germany). The artificial root canal support moved in a pure axial motion through a lineal guide (Ref.: HGH35C 10249-1 001 MA, HIWIN Technologies Corp., Taichung, Taiwan). The endodontic rotary file selected (Plex V2 ${ }^{\circledR}$, Orodeka) was digitized using a micro Computer Tomography (Skyscan 1176, Bruker-MicroCT, Kontich, Belgium) to obtain a stereolithography (STL) file (Figure 2A) that was needed to design an accurate artificial root canal regarding the measurements of the endodontic rotary file tested (Figure 2B). The artificial root canal piece was manufactured with stainless steel with a $1 \mathrm{~mm}$ width. The artificial root canal form was anatomically based and designed using 2D/3D CAD/CAE software (Midas FX+ ${ }^{\circledR}$, Brunleys), and it was manufactured by electrical discharge machining (EDM) molybdenum wire-cut technology (Cocchiola S.A., Buenos Aires, Argentina) (Figure 2C) to simulate the tested endodontic rotary instrument's apical size, taper, and length and enable intimate contact between the endodontic rotary file and the artificial root canal, with a $60^{\circ}$ curvature according to Schneider's measure technique [16] and a $3 \mathrm{~mm}$ radius of curvature (Figure 2D). 

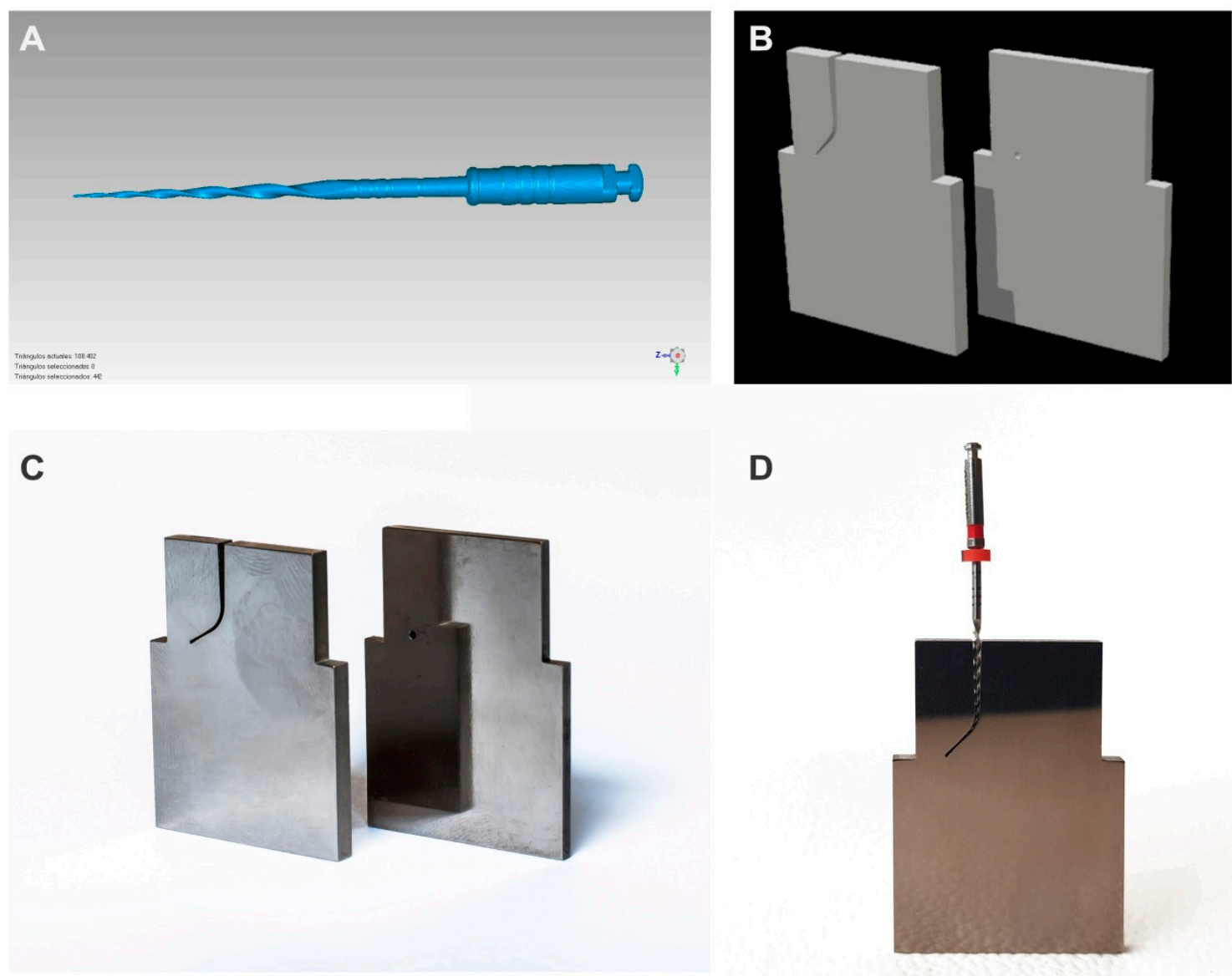

Figure 2. (A) Stereolithography (STL) file of the endodontic rotary file; (B) STL file of the artificial root canal; (C) artificial root canal manufactured by electrical discharge machining (EDM) and (D) endodontic rotary file in intimate contact with the artificial root canal (D).

The failure of the endodontic rotary instrument (Figure 2B) was detected through a LightDependent Resistor (LDR) sensor (Ref.: C000025, Arduino LLC ${ }^{\circledR}$, Ivrea, Italy) located at the apex of the artificial root canal. The LDR sensor quantifies the continuous light source emitted by a high-brightness white Light-Emitting Diode (LED) (20000 mcd) (Ref.: 12.675/5/b/c/20k, Batuled, Coslada, Spain), which is opposite to the artificial root canal (Figure 1). The LDR (Ref.: C000025, Arduino LLC ${ }^{\circledR}$ ) sensor data were conditioned by a processor (Arduino UNO Rev. 3, Arduino LLC ${ }^{\circledR}$, Ivrea, Italy) (Figure 1) to detect values from 0 (endodontic rotary instrument inside the artificial root canal) to 1024 (endodontic rotary instrument outside the artificial root canal). The time to failure was determined when the LDR (Ref.: C000025, Arduino LLC ${ }^{\circledR}$ ) sensor detected no variations in light values for $50 \mathrm{~ms}$. The hardware was managed by software that receives input signals from the Arduino board (Figure 3A-C). The signals were detected by the LDR (Ref.: C000025, Arduino LLC ${ }^{\circledR}$ ) sensor with a frequency of $50 \mathrm{~ms}$ to accurately detect the time of failure.

Once the LDR (Ref.: C000025, Arduino LLC ${ }^{\circledR}$ ) sensor detects the failure of the endodontic rotary instrument, the brushed DC gearmotor stops immediately, and the time to failure and the test parameters are saved by the management software. In addition, the manager application sends output data that start each cyclic fatigue test and control the speed of the pecking motion of the artificial root canal. The speed of the movement and the LDR (Ref.: C000025, Arduino LLC ${ }^{\circledR}$ ) sensor values were also shown in real time on a Liquid Crystal Display (LCD) (Ref.: LCD-09568, Spark Fun Electronics, Niwot, CO, USA) placed on the structure of the device (Figure 1). 


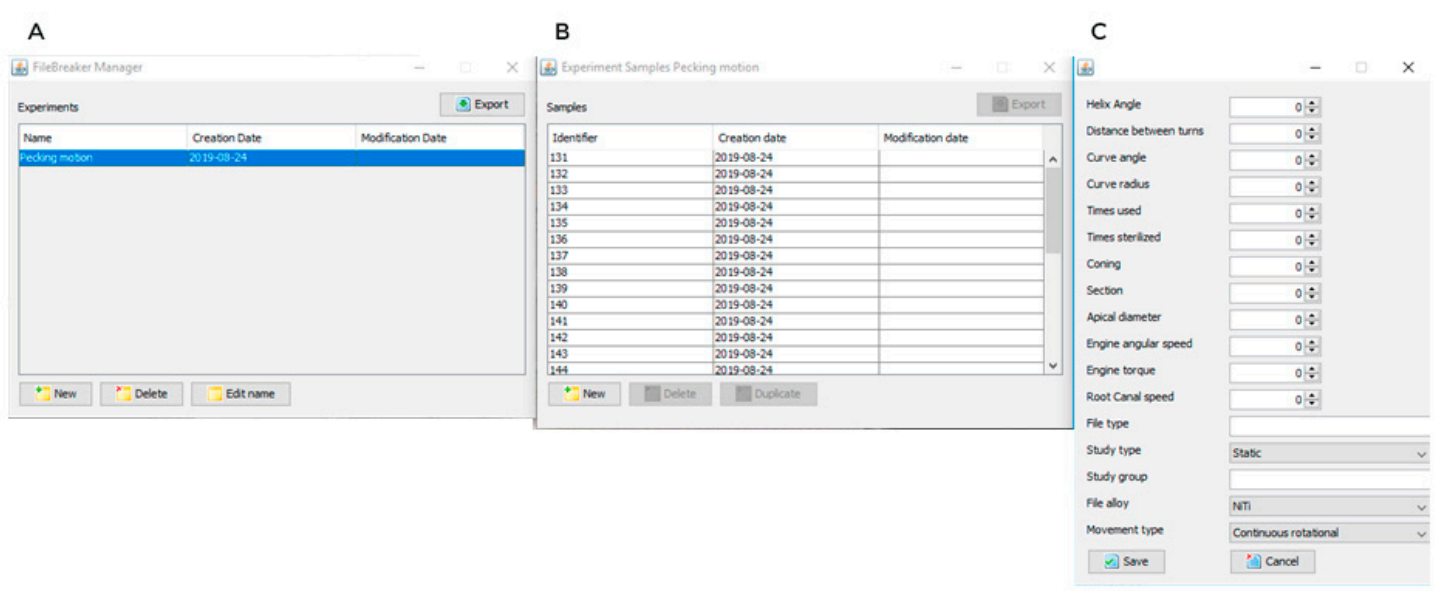

Figure 3. The management software $(\mathbf{A}, \mathbf{B})$ that managed the cyclic fatigue device with configurable parameters (C).

The endodontic rotary instruments were operated by a 6:1 reduction handpiece (X-Smart Plus, Dentsply Maillefer) and a torque-controlled motor with continuous rotation at $400 \mathrm{rpm}$ and $3.5 \mathrm{~N} / \mathrm{cm}$ torque according to the manufacturer's instructions. The friction between the file and the artificial canal walls was reduced by applying special high-flow synthetic oil designed for the lubrication of mechanical parts (Singer All-Purpose Oil; Singer Sewing Company, Barcelona, Spain).

All endodontic rotary instruments were rotated until fracture occurred. The number of cycles to fracture $(\mathrm{NCF})$ for each instrument was calculated by using the following formula: $\mathrm{NCF}=$ time (seconds) to failure $\times$ rotational speed $(\mathrm{rpm}) / 60$ seconds [17]. The time to failure, the NCF, the number of in-and-out movements, and the length of the fracture file tip were also measured and recorded. Fractographic analysis of the failure was performed under a scanning electron microscope (ZEISS Supra 35VP; Oberkochen, GmBH, Germany) to examine topographic features of the fractured endodontic rotary files.

\subsection{Statistical Tests}

Statistical analysis of all variables was carried out using SAS 9.4 (SAS Institute Inc., Cary, NC, USA). Descriptive statistics are expressed as means and standard deviations (SD) for quantitative variables and as absolute numbers and percentages for qualitative variables. Comparative analysis was performed by comparing the time to failure, the NCF, and the number of pecking movements (cycles of in-and-out movements) using ANOVA. In addition, Weibull characteristic strength $(\sigma 0)$ and Weibull modulus $(\mathrm{m})$ were calculated. The statistical significance was set at $p<0.05$.

\section{Results}

The means and SD values for the time to failure (seconds), the NCF, and the number of cycles of in-and-out movement in the study groups are displayed in Tables 1-3, respectively.

Table 1. Descriptive statistics of the time to failure.

\begin{tabular}{ccccccc}
\hline & $\boldsymbol{n}$ & Mean & SD & Minimum & Maximum & Fracture Length (mm) \\
\hline 30 MOV/MIN & 20 & $423.66^{\mathrm{a}}$ & 84.61 & 216.23 & 544.40 & 3.23 \\
60 MOV/MIN & 20 & $234.23^{\mathrm{b}}$ & 60.56 & 127.00 & 378.21 & 3.04 \\
$120 \mathrm{MOV} / \mathrm{MIN}$ & 20 & $163.06^{\mathrm{c}}$ & 45.95 & 81.80 & 241.16 & 3.81 \\
\hline
\end{tabular}

$\mathrm{SD}$, standard deviations; ${ }^{\mathrm{a}}, \mathrm{b}, \mathrm{c}$, different superscript means statistically significant differences between groups $(p<0.05)$. 
Table 2. Descriptive statistics of the NCF.

\begin{tabular}{ccccccc}
\hline & $\boldsymbol{n}$ & Mean & SD & Minimum & Maximum & Fracture Length (mm) \\
\hline 30 MOV/MIN & 20 & $2824.37^{\mathrm{a}}$ & 564.05 & 1441.55 & 3629.35 & 3.23 \\
60 MOV/MIN & 20 & $1560.55^{\mathrm{b}}$ & 401.23 & 846.69 & 2501.41 & 3.04 \\
120 MOV/MIN & 20 & $1087.06^{\mathrm{c}}$ & 306.34 & 545.33 & 1607.73 & 3.81 \\
\hline
\end{tabular}

$\mathrm{NCF}$, the number of cycles to failure; ${ }^{\mathrm{a}}, \mathrm{b},{ }^{\mathrm{c}}$, different superscript means statistically significant differences between groups $(p<0.05)$.

Table 3. Descriptive statistics of the number of cycles of in-and-out movement.

\begin{tabular}{ccccccc}
\hline & $\boldsymbol{n}$ & Mean & SD & Minimum & Maximum & Fracture Length (mm) \\
\hline 30 MOV/MIN & 20 & $211.60^{\mathrm{a}}$ & 42.66 & 108.12 & 272.20 & 3.23 \\
$60 \mathrm{MOV} / \mathrm{MIN}$ & 20 & $234.23^{\mathrm{b}}$ & 60.56 & 127.00 & 378.21 & 3.04 \\
$120 \mathrm{MOV} / \mathrm{MIN}$ & 20 & $326.12^{\mathrm{b}}$ & 91.90 & 163.59 & 482.32 & 3.81 \\
\hline a b ${ }^{\mathrm{b}}$ different superscript means statistically significant differences between groups $(p<0.05)$.
\end{tabular}

The ANOVA revealed statistically significant differences in all three variables. The differences revealed by pairwise comparisons were all statistically significant, except for the difference in the number of cycles between the groups with 60 and 120 movements $/ \mathrm{min}(p=0.298)$. The scale distribution parameter $(\eta)$ of Weibull statistics showed statistically significant differences in all three variables, except for the difference in the number of cycles between the groups with 30 and 60 movements/min $(p=0.0722)$ (Tables 4-6).

Table 4. Weibull statistics of the time to failure.

\begin{tabular}{ccccccccc}
\hline & \multicolumn{3}{c}{$\mathbf{m}=$ Weibull Shape $(\boldsymbol{\beta})$} & \multicolumn{3}{c}{$\boldsymbol{\sigma}_{\mathbf{0}}=$ Weibull Scale $(\boldsymbol{\eta})$} \\
\cline { 2 - 9 } & Estimate & St Error & Lower & Upper & Estimate & St Error & Lower & Upper \\
\hline $30 \mathrm{MOV} / \mathrm{MIN}$ & 6.3802 & 1.1533 & 4.4768 & 9.0927 & 455.9851 & 16.7468 & 424.3155 & 490.0185 \\
$60 \mathrm{MOV} / \mathrm{MIN}$ & 4.2152 & 0.6990 & 3.0456 & 5.8341 & 257.1689 & 14.4489 & 230.3531 & 287.1065 \\
$120 \mathrm{MOV} / \mathrm{MIN}$ & 4.4090 & 0.8177 & 3.0653 & 6.3417 & 179.5190 & 9.5319 & 161.7759 & 199.2080 \\
\hline
\end{tabular}

Table 5. Weibull statistics of the NCF.

\begin{tabular}{lcccccccc}
\hline & \multicolumn{3}{c}{$\mathbf{m}=$ Weibull Shape $(\beta)$} & \multicolumn{3}{c}{$\boldsymbol{\sigma}_{\mathbf{0}}=$ Weibull Scale $(\eta)$} \\
\cline { 2 - 9 } & Estimate & St Error & Lower & Upper & Estimate & St Error & Lower & Upper \\
\hline $30 \mathrm{MOV} / \mathrm{MIN}$ & 6.3802 & 1.1533 & 4.4768 & 9.0927 & 3039.9005 & 111.6454 & 2828.7697 & 3266.7895 \\
$60 \mathrm{MOV} / \mathrm{MIN}$ & 4.2540 & 0.7079 & 3.0702 & 5.8944 & 1712.7561 & 95.3373 & 1535.7306 & 1910.1877 \\
$120 \mathrm{MOV} / \mathrm{MIN}$ & 4.4090 & 0.8177 & 3.0653 & 6.3417 & 1196.7927 & 63.5463 & 1078.5059 & 1328.0528 \\
\hline
\end{tabular}

Table 6. Weibull statistics of the number of cycles of in-and-out movement.

\begin{tabular}{ccccccccc}
\hline & \multicolumn{3}{c}{$\mathbf{m}=$ Weibull Shape $(\beta)$} & \multicolumn{3}{c}{$\boldsymbol{\sigma}_{\mathbf{0}}=$ Weibull Scale $(\eta)$} \\
\cline { 2 - 9 } & Estimate & St Error & Lower & Upper & Estimate & St Error & Lower & Upper \\
\hline $30 \mathrm{MOV} / \mathrm{MIN}$ & 6.3342 & 1.1474 & 4.4412 & 9.0341 & 227.8707 & 8.4275 & 211.9375 & 245.0018 \\
$60 \mathrm{MOV} / \mathrm{MIN}$ & 4.2152 & 0.6990 & 3.0456 & 5.8341 & 257.1689 & 14.4489 & 230.3531 & 287.1065 \\
$120 \mathrm{MOV} / \mathrm{MIN}$ & 4.4090 & 0.8177 & 3.0653 & 6.3416 & 359.0376 & 19.0640 & 323.5513 & 398.4160 \\
\hline
\end{tabular}

However, the shape distribution parameter $(\beta)$ showed no statistically significant differences in the time to failure between the groups with 30 and 60 movements/min $(p=0.0911), 30$ and 120 movements/min ( $p=0.1537)$, and 60 and 120 movements/min ( $p=0.8568)$ (Figures 4 and 5).

There were no statistically significant differences in the $\beta$ value of the NCF between the groups with 30 and 60 movements/min $(p=0.0990), 30$ and 120 movements $/ \mathrm{min}(p=0.1537)$, and 60 and 120 movements/min ( $p=0.8858)$ (Figures 6 and 7). 


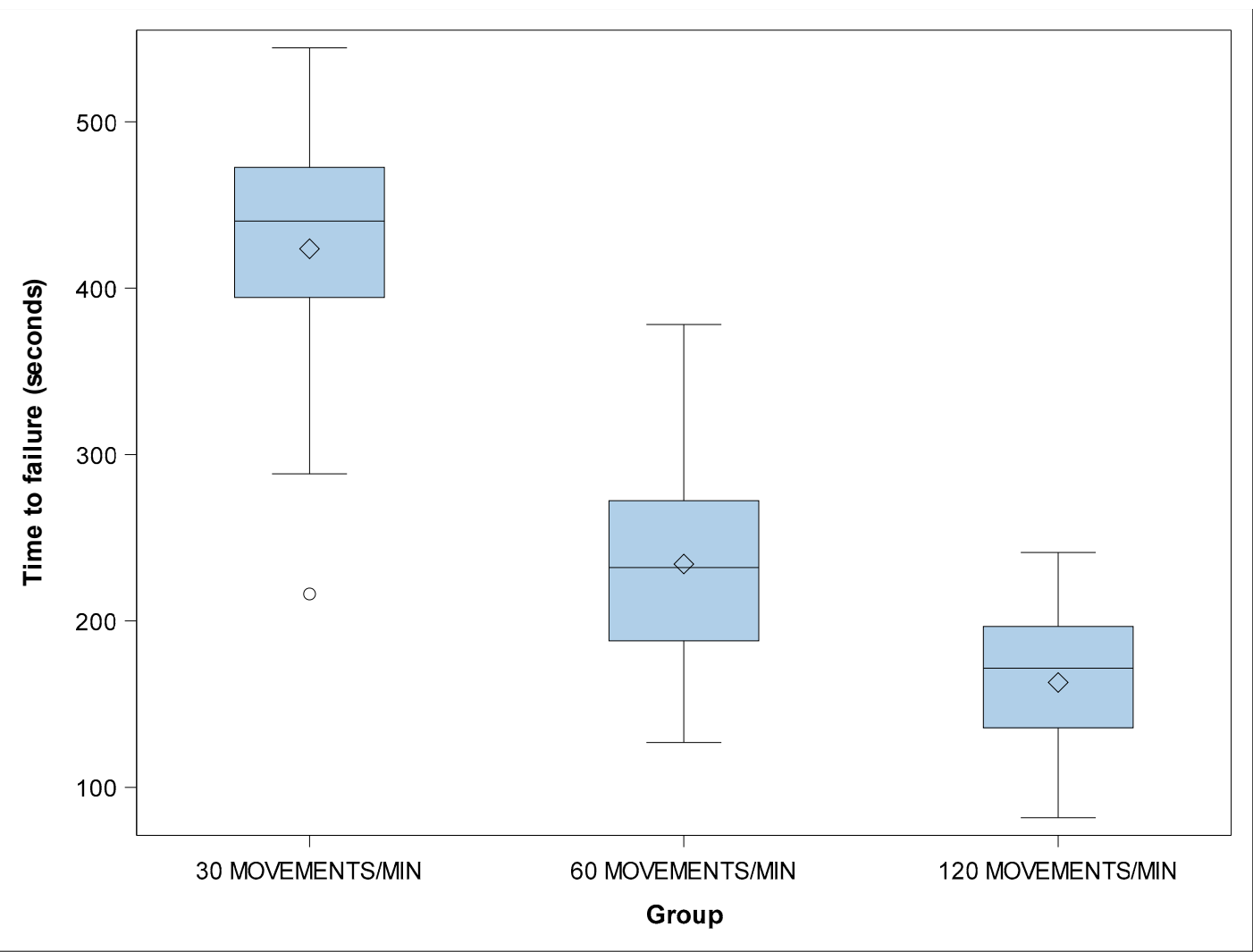

Figure 4. Boxplots of the time to failure of the experimental groups. The horizontal line in each box represents the median value.

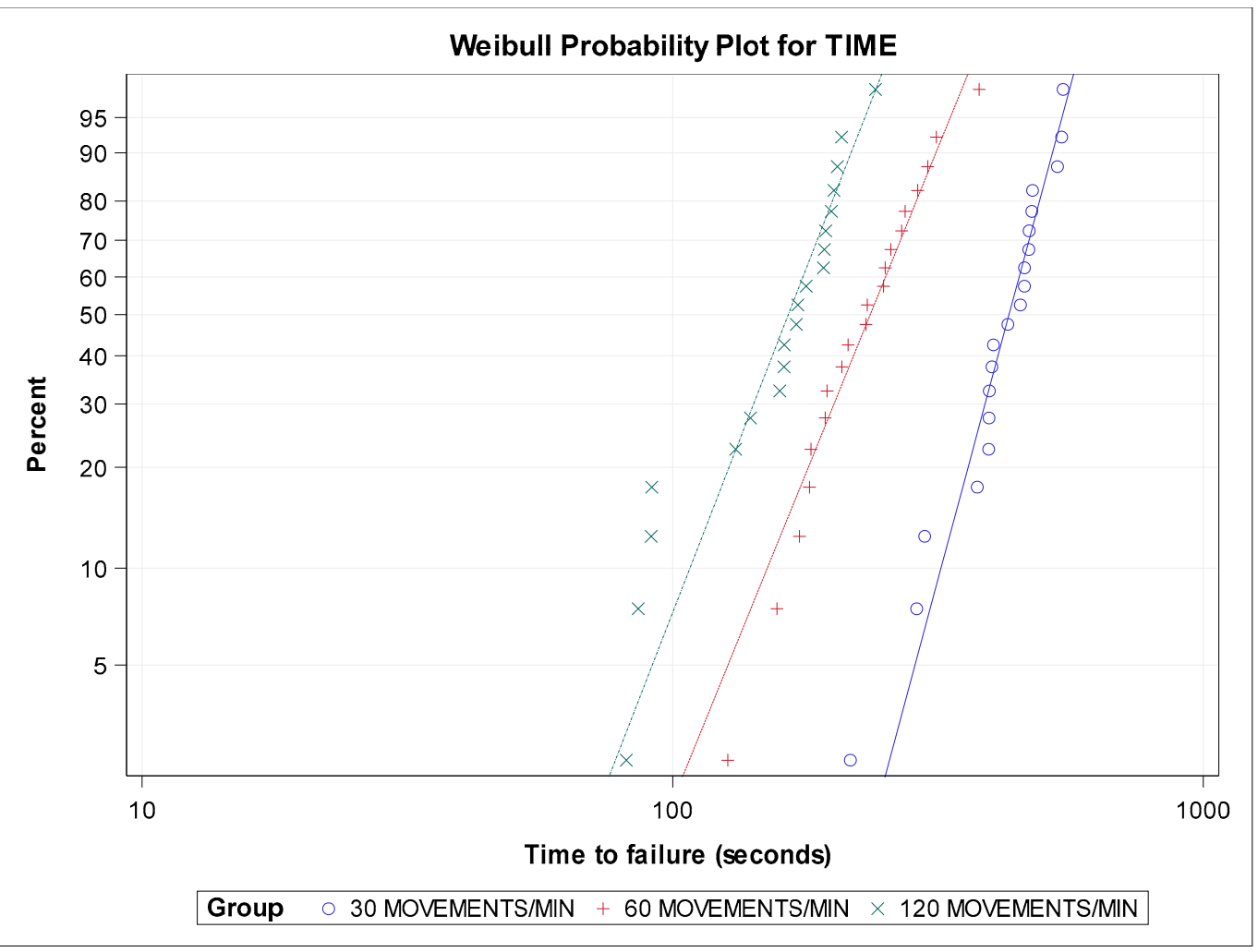

Figure 5. Weibull probability plot of the time to failure. 


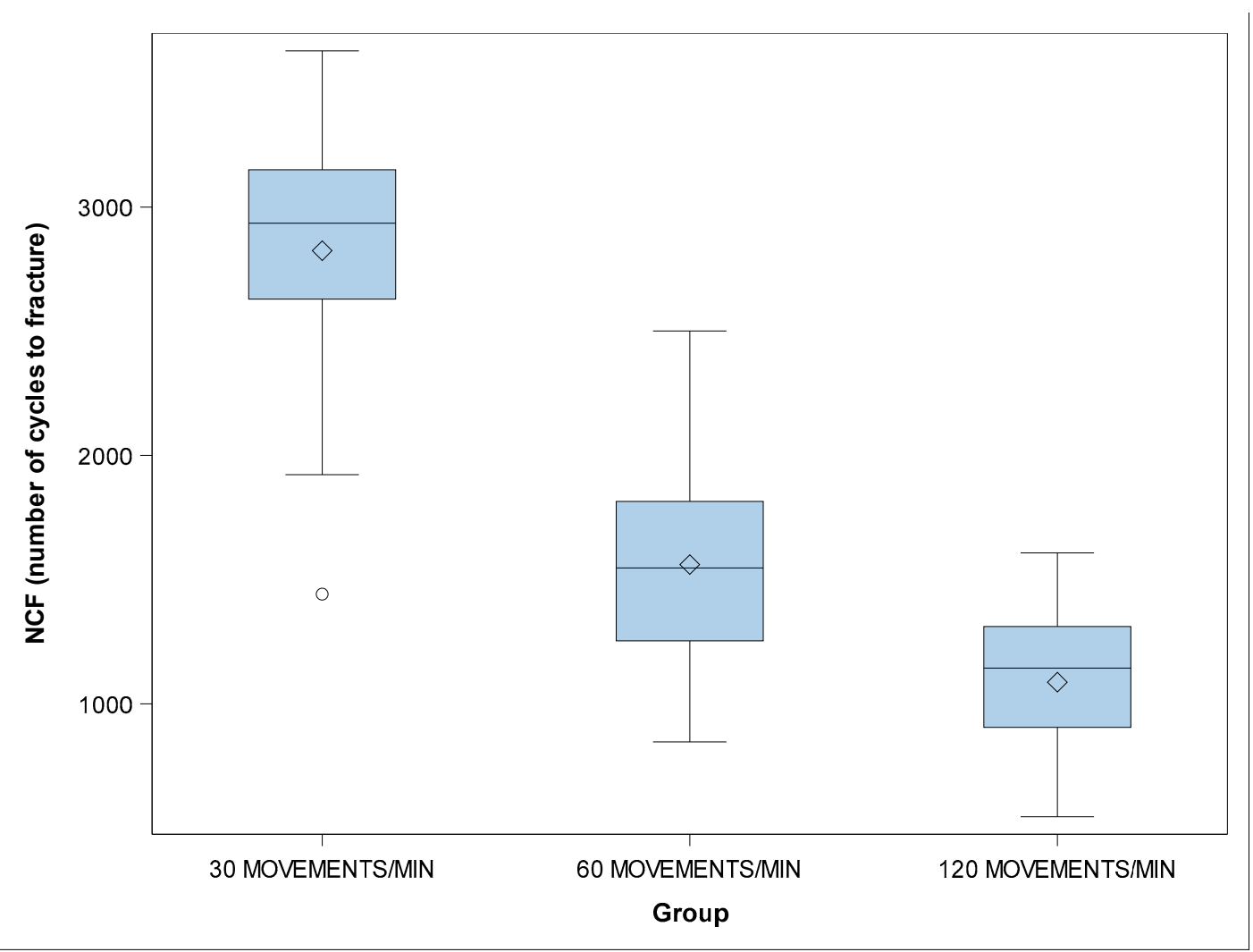

Figure 6. Boxplots of the NCF of the experimental groups. The horizontal line in each box represents the median value.

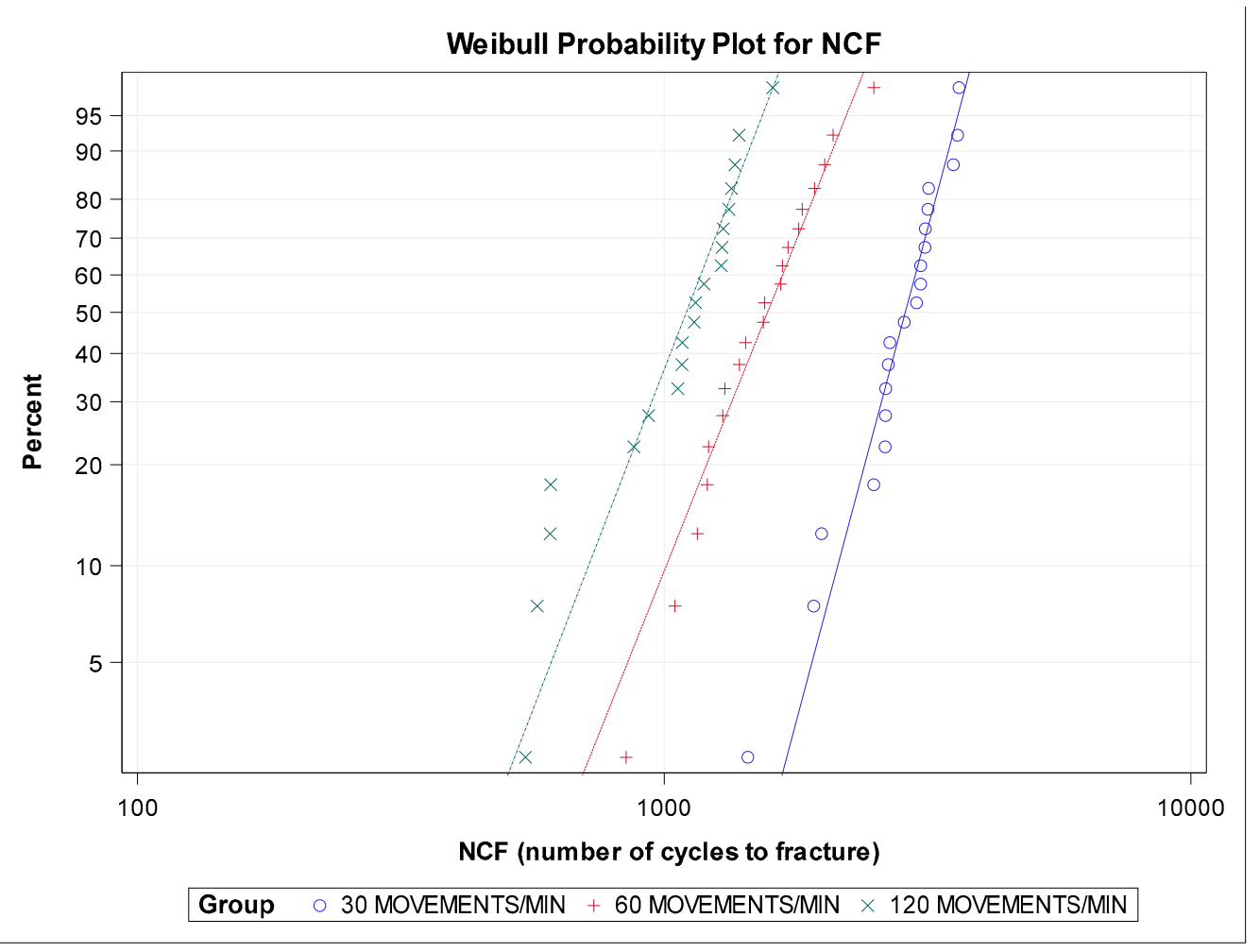

Figure 7. Weibull probability plot of the NCF. 
There were no statistically significant differences in the $\beta$ value of the number of cycles of in-and-out movement between the groups with 30 and 60 movements/min $(p=0.0990), 30$ and 120 movements $/ \mathrm{min}(p=0.1537)$, and 60 and 120 movements $/ \min (p=0.8858)$ (Figures 8 and 9$)$.

The lifespan of the endodontic rotary files submitted to 30 movements/min was higher $(430.53 \pm 77.71 \mathrm{~s}$ than that of instruments submitted to 60 movements $/ \mathrm{min}(235.75 \pm 62.55 \mathrm{~s})$ and 120 movements/min $(165.20 \pm 42.03 \mathrm{~s})$. The mean lengths of the fractured fragments were not statistically significantly different for any of the instruments tested $(p>0.05)$.

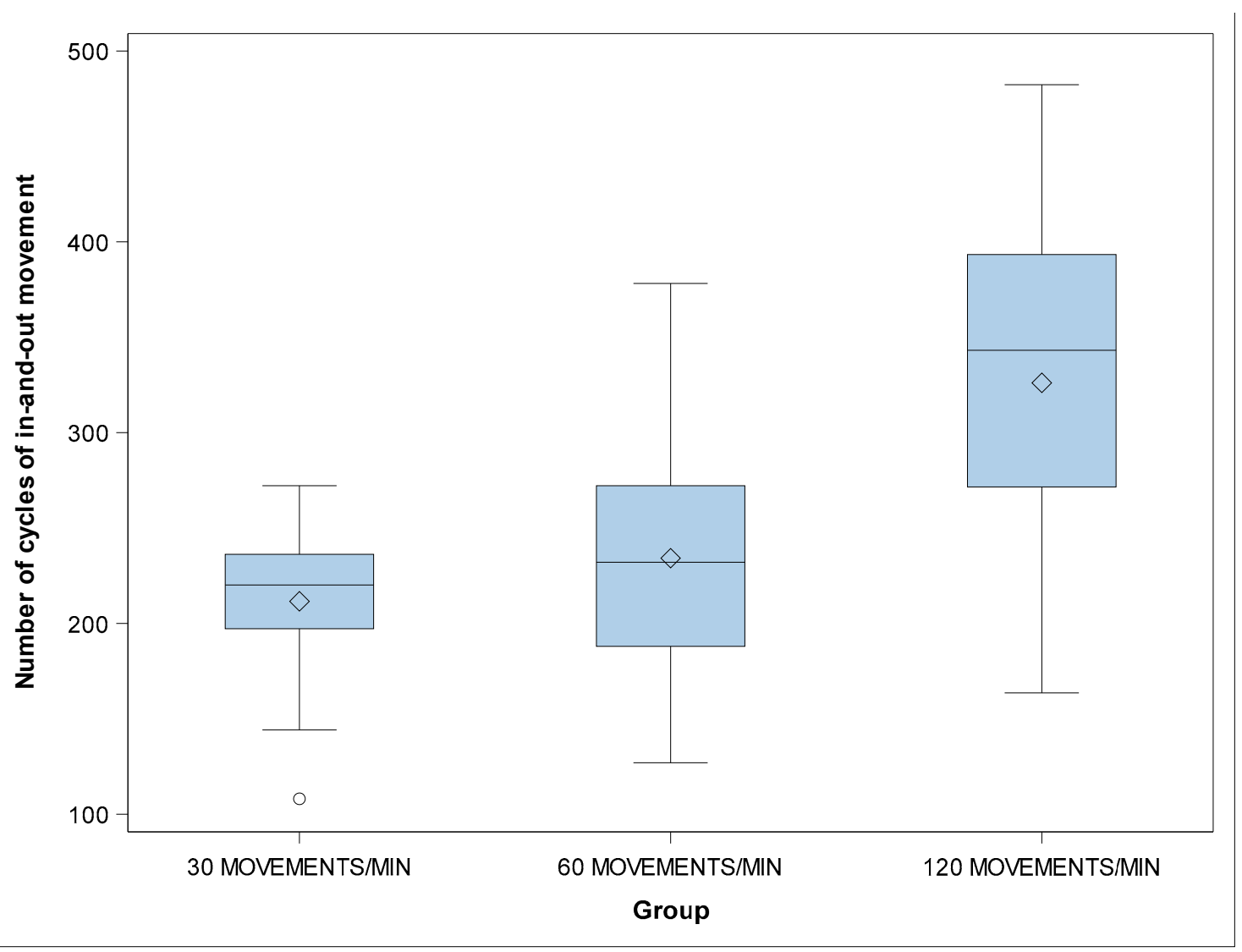

Figure 8. Boxplots of the number of cycles of in-and-out movement of the experimental groups. The horizontal line in each box represents the median value. 


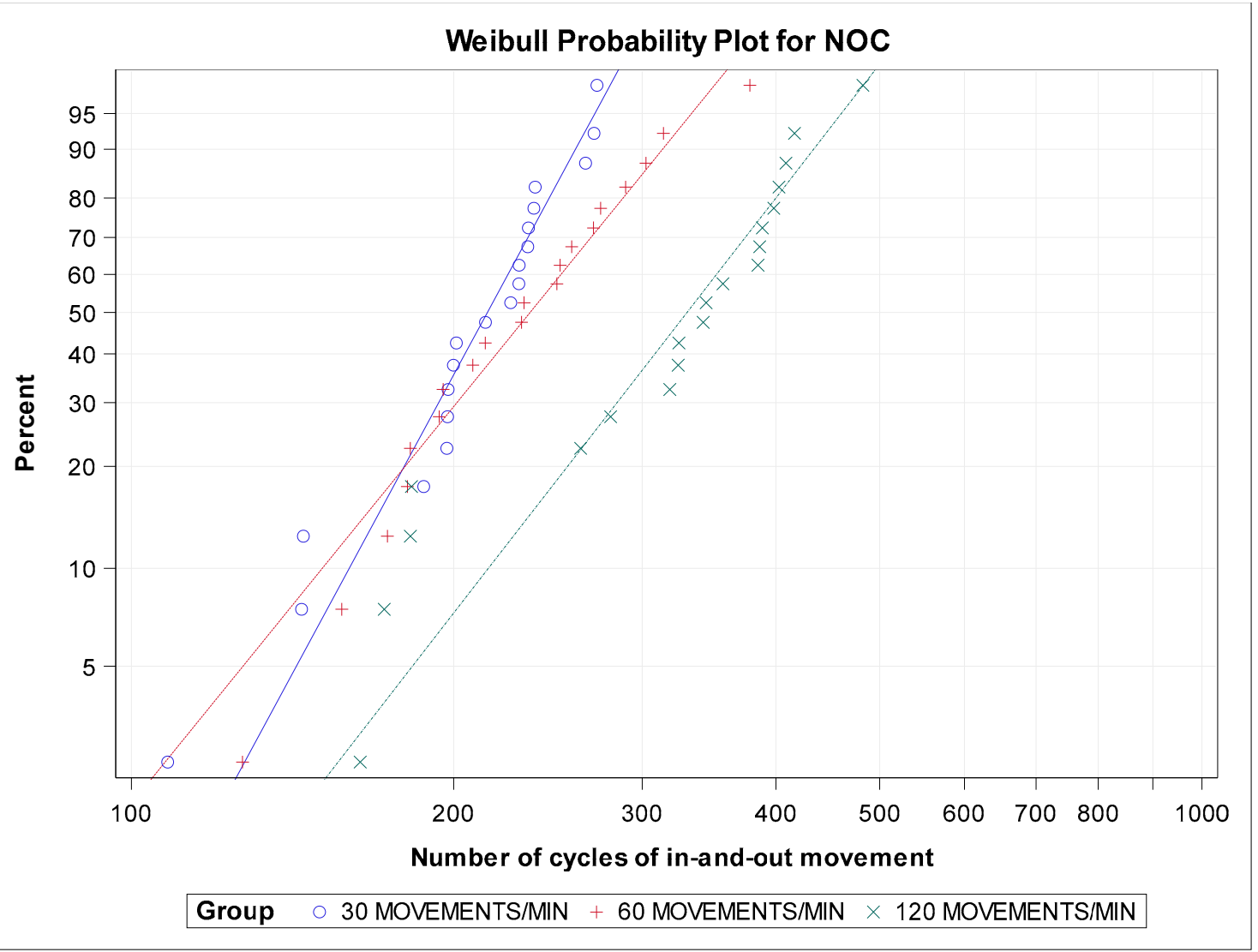

Figure 9. Weibull probability plot of the number of cycles of in-and-out movement.

\section{Discussion}

The results obtained in the present study lead to the rejection of the null hypothesis (H0), which states that the frequency of pecking motion has no statistically significant effect on the cyclic fatigue resistance of endodontic rotary instruments.

Different causes of fractures of endodontic instruments have been proposed by many authors and include operator experience [18,19], rotational speed [20,21], the number of uses [22], the number of rotations [23], pre-flaring [24], glide path [25], the angle and radius of the curvature [20,26], and the sterilization of instruments [27]. However, the influence of the frequency of pecking motion performed by the operator on the cyclic fatigue resistance of endodontic rotary instruments has not yet been analyzed.

Cyclic fatigue resistance has been experimentally analyzed by using several custom-made devices; however none of them have been capable of testing the cyclic fatigue resistance of NiTi endodontic rotary instruments using an anatomically based artificial root canal that allows intimate contact between the artificial root canal and the endodontic rotary instrument along the file, which might alter the cyclic fatigue resistance of the endodontic rotary instruments and hence the results of the experiment [11]. The dynamic motion produced by a cyclic fatigue test device can be made comparable to the pecking motion performed by the operator during a root canal treatment. The automatic detection system is able to objectively and accurately identify failures of endodontic rotary files.

Dederich and Zakariasen (1986) were first to develop a dynamic testing device, which allowed the endodontic rotary instruments to realize displacement in a pure axial movement [28]. Ray et al. (2007) also performed dynamic cyclic fatigue studies with standardized axial movement, and they concluded that the pecking motion increased the lifespan of the endodontic rotary instruments submitted to cyclic fatigue compared with the results obtained from static cyclic fatigue studies [29]. Hülsmann 
et al. (2019) reported similar findings to ours and highlighted the differences between static and dynamic cyclic fatigue tests [30]. Nevertheless, only $12 \%$ of published cyclic fatigue studies have used a dynamic fatigue device [30]. Most studies that have compared static and dynamic cyclic fatigue studies have concluded that the time to fracture of endodontic rotary instruments submitted to dynamic cyclic fatigue studies was approximately $20-40 \%$ higher than that found in static cyclic fatigue studies [26,31-35]. Previous dynamic cyclic fatigue devices have been unable to accurately identify the causes of endodontic rotary instrument failures because of the absence of standardization of the axial direction of the pecking motion. Lateral movements during the pecking motion of an endodontic rotary instrument can lead to a second bending point at the beginning of the artificial root canal, thus distorting the outcome of cyclic fatigue tests. In addition, Plotino et al. (2010) reported the influence of the shape of the artificial root canal on the contact between the endodontic rotary instrument and the artificial root canal. They concluded that artificial root canals must be designed with a focus on the shape of the endodontic rotary file being studied [36]. However, the above-described artificial root canals had a cylindrically shaped circular section that did not allow intimate contact with the endodontic rotary instrument. In an attempt to simulate real clinical conditions, the present study involved an artificial root canal that was designed by using the measurements of the endodontic rotary instrument being studied.

The higher $\beta$ values observed for the group with 30 movements/min for all three variables reveal more predictable behavior of the failure of the endodontic rotary instruments in this study group, and the lower $\eta$ values found in the groups with 60 and 120 movements/min for all three variables indicate a lower cyclic fatigue resistance of the endodontic rotary instruments in these study groups. The location of the crystal structure transformation is changed in the endodontic rotary instrument during the pecking motion, which increases the cyclic fatigue resistance [30].

The conclusion derived from this study is that a high frequency of pecking motion decreases the cyclic fatigue resistance of endodontic rotary files.

Nevertheless, further research is needed to determine the influence of the frequency of pecking motion and working time on the cyclic fatigue resistance of endodontic rotary files.

\section{Conclusions}

In conclusion, within the limitations of this study, our results show that a high frequency of pecking motion decreases the cyclic fatigue resistance of endodontic rotary instruments. A low frequency of pecking motion is recommended to reduce the risk of fractures of endodontic rotary instruments associated with cyclic fatigue.

Author Contributions: All of the authors contributed to the investigation, supervision, writing, review, and editing of the study. The study was conceptualized by R.A.-P., J.M.Á., A.A.M., Á.Z.-M., and J.J.S.-E. Data curation, data visualization, and analysis were carried out by J.C.B., R.L.P., and Ó.A.-E. All authors have read and agreed to the published version of the manuscript.

Acknowledgments: The authors would like to thank Santiago López Martínez for his invaluable assistance in this study.

Conflicts of Interest: The authors declare no conflict of interest.

\section{References}

1. Peters, O.A. Current challenges and concepts in the preparation of root canal systems: A review. J. Endod. 2004, 30, 559-567. [CrossRef] [PubMed]

2. Pedullà, E.; Lo Savio, F.; Boninelli, S.; Plotino, G.; Grande, N.M.; La Rosa, G.; Rapisarda, E. Torsional and Cyclic Fatigue Resistance of a New Nickel-Titanium Instrument Manufactured by Electrical Discharge Machining. J. Endod. 2016, 42, 156-159. [CrossRef] [PubMed]

3. Walia, H.; Brantley, W.A.; Gerstein, H. An initial investigation of the bending and torsional properties of Nitinol root canal files. J. Endod. 1988, 14, 346-351. [CrossRef] 
4. Li, U.M.; Lee, B.S.; Shih, C.T.; Lan, W.H.; Lin, C.P. Cyclic fatigue of endodontic nickel titanium rotary instruments: Static and dynamic tests. J. Endod. 2002, 28, 448-451. [CrossRef] [PubMed]

5. Gutmann, J.L.; Gao, Y. Alteration in the inherent metallic and surface properties of nickel-titanium root canal instruments to enhance performance, durability and safety: A focused review. Int. Endod. J. 2012, 45, 113-128. [CrossRef]

6. Pirani, C.; Cirulli, P.P.; Chersoni, S.; Micele, L.; Ruggeri, O.; Prati, C. Cyclic fatigue testing and metallographic analysis of nickel-titanium rotary instruments. J. Endod. 2011, 37, 1013-1016. [CrossRef]

7. De Arruda Santos, L.; Bahia, M.G.; de Las Casas, E.B.; Buono, V.T. Comparison of the mechanical behaviour between controlled memory and superelastic nickel-titanium files via Finite Element Analysis. J. Endod. 2013, 39, 1444-1447. [CrossRef]

8. Plotino, G.; Testarelli, L.; Al-Sudani, D.; Pongione, G.; Grande, N.M.; Gambarini, G. Fatigue resistance of rotary instruments manufactured using different nickel-titanium alloys: A comparative study. Odontology 2014, 102, 31-35. [CrossRef]

9. Sattapan, B.; Nervo, G.J.; Palamara, J.E.; Messer, H.H. Defects in rotary nickel titanium files after clinical use. J. Endod. 2000, 26, 161-165. [CrossRef]

10. Inan, U.; Gonulol, N. Deformation and fracture of Mtwo rotary nickel-titanium instruments after clinical use. J. Endod. 2009, 35, 1396-1399. [CrossRef]

11. Plotino, G.; Grande, N.M.; Cordaro, M.; Testarelli, L.; Gambarini, G. A review of cyclic fatigue testing of nickel-titanium rotary instruments. J. Endod. 2009, 35, 1469-1476. [CrossRef] [PubMed]

12. Bhagabati, N.; Yadav, S.; Talwar, S. An in vitro cyclic fatigue analysis of different endodontic nickel-titanium rotary instruments. J. Endod. 2012, 38, 515-518. [CrossRef] [PubMed]

13. Lopes, H.P.; Gambarra-Soares, T.; Elias, C.N.; Siqueira, J.F.; Inojosa, I.F.; Lopes, W.S.; Vieira, V.T. Comparison of the mechanical properties of rotary instruments made of conventional nickel-titanium wire, M-wire, or nickel-titanium alloy in R-phase. J. Endod. 2013, 39, 516-520. [CrossRef] [PubMed]

14. ANSI/ADA. Root Canal Files and Reamers, Type K for Hand Use; Specification N N28-2002; American Dental Association: Chicago, IL, USA, 2002.

15. ISO. ISO 3630-3631: Dentistry—Root Canal Instruments_Part 1: General Requirements and Test Methods; ISO: Geneva, Switzerland, 2008.

16. Schneider, S.W. A comparison of canal preparations in straight and curved root canals. Oral Surg. Oral Med. Oral Pathol. 1971, 32, 271-275. [CrossRef]

17. Topçuoğlu, H.S.; Topçuoğlu, G.; Akti, A.; Düzgün, S. In vitro comparison of cyclic fatigue resistance of ProTaper Next, HyFlex CM, OneShape, and ProTaper Universal instruments in a canal with a double curvature. J. Endod. 2016, 42, 969-971. [CrossRef]

18. Mandel, E.; Adib-Yazdi, M.; Benhamou, L.M.; Lachkar, T.; Mesgouez, C.; Sobel, M. Rotary Ni-Ti profile systems for preparing curved canals in resin blocks: Influence of operator on instrument breakage. Int. Endod. J. 1999, 32, 436-443. [CrossRef]

19. Yared, G.M.; Dagher, F.E.; Machtou, P.; Kulkarni, G.K. Influence of rotational speed, torque and operator proficiency on failure of Greater Taper files. Int. Endod. J. 2002, 35, 7-12. [CrossRef]

20. Zelada, G.; Varela, P.; Martín, B.; Bahillo, J.G.; Magán, F.; Ahn, S. The effect of rotational speed and the curvature of root canals on the breakage of rotary endodontic instruments. J. Endod. 2002, 28, 540-542. [CrossRef]

21. Martín, B.; Zelada, G.; Varela, P.; Bahillo, J.G.; Magán, F.; Ahn, S.; Rodríguez, C. Factors influencing the fracture of nickel-titanium rotary instruments. Int. Endod. J. 2003, 36, 262-266. [CrossRef]

22. Parashos, P.; Gordon, I.; Messer, H.H. Factors influencing defects of rotary nickel-titanium instruments after clinical use. J. Endod. 2004, 30, 722-725. [CrossRef]

23. Ferreira, F.; Adeodato, C.; Barbosa, I.; Aboud, L.; Scelza, P.; Zaccaro Scelza, M. Movement kinematics and cyclic fatigue of NiTi rotary instruments: A systematic review. Int. Endod. J. 2017, 50, 143-152. [CrossRef] [PubMed]

24. Roland, D.D.; Andelin, W.E.; Browning, D.F.; Hsu, G.-H.R.; Torabinejad, M. The effect of preflaring on the rates of separation for 0.04 taper nickel titanium rotary instruments. J. Endod. 2002, 28, 543-545. [CrossRef] [PubMed]

25. Patiño, P.V.; Biedma, B.M.; Liébana, C.R.; Cantatore, G.; Bahillo, J.G. The influence of manual glide path on the separation rate of NiTi rotary instruments. J. Endod. 2005, 31, 114-116. [CrossRef] [PubMed] 
26. Gambarini, G.; Galli, M.; Di Nardo, D.; Seracchiani, M.; Donfrancesco, O.; Testarelli, L. Differences in cyclic fatigue lifespan between two different heat treated NiTi endodontic rotary instruments: WaveOne Gold vs EdgeOne Fire. J. Clin. Exp. Dent. 2019, 11, 609-613. [CrossRef] [PubMed]

27. Hilfer, P.B.; Bergeron, B.E.; Mayerchak, M.J.; Roberts, H.W.; Jeansonne, B.G. Multiple autoclave cycle effects on cyclic fatigue of nickel-titanium rotary files produced by new manufacturing methods. J. Endod. 2011, 37, 72-74. [CrossRef] [PubMed]

28. Dederich, D.N.; Zakariasen, K.L. The effects of cyclical axial motion on rotary endodontic instrument fatigue. Oral Surg. Oral Med. Oral Pathol. 1986, 61, 192-196. [CrossRef]

29. Ray, J.J.; Kirkpatrick, T.C.; Rutledge, R.E. Cyclic fatigue of EndoSequence and K3 rotary files in a dynamic model. J. Endod. 2007, 33, 1469-1472. [CrossRef]

30. Hülsmann, M.; Donnermeyer, D.; Schäfer, E. A critical appraisal of studies on cyclic fatigue resistance of enginedriven endodontic instruments. Int. Endod. J. 2019, 52, 1427-1445. [CrossRef]

31. Lopes, H.P.; Britto, I.M.; Elias, C.N.; Machado de Oliveira, J.C.; Neves, M.A.; Moreira, E.J.; Siqueira, J.F. Cyclic fatigue resistance of ProTaper Universal instruments when subjected to static and dynamic tests. Oral Surg. Oral Med. Oral Pathol. Oral Radiol. Endod. 2010, 110, 401-404. [CrossRef]

32. Lopes, H.P.; Elias, C.N.; Vieira, M.V.; Siqueira, J.F.; Mangelli, M.; Lopes, W.S.; Vieira, V.T.; Alves, F.R.; Oliveira, J.C.; Soares, T.G. Fatigue life of Reciproc and Mtwo instruments subjected to static and dynamic tests. J. Endod. 2013, 39, 693-696. [CrossRef]

33. Rodrigues, R.C.; Lopes, H.P.; Elias, C.N.; Amaral, G.; Vieira, V.T.; De Martin, A.S. Influence of different manufacturing methods on the cyclic fatigue of rotary nickel-titanium endodontic instruments. J. Endod. 2011, 37, 1553-1557. [CrossRef] [PubMed]

34. Gambarra-Soares, T.; Lopes, H.P.; Olivieira, J.C.M.; Chaves Souza, L.; Vieira, V.T.L.; Elias, C.N. Dynamic or static cyclic fatigue tests: Which best determines the lifespan of endodontic files? ENDO Endod. Pract. Today 2013, 7, 101-104.

35. De-Deus, G.; Vieira, V.T.; da Silva, E.J.; Lopes, H.; Elias, C.N.; Moreira, E.J. Bending resistance and dynamic and static cyclic fatigue life of Reciproc and WaveOne large instruments. J. Endod. 2014, 40, 575-579. [CrossRef] [PubMed]

36. Plotino, G.; Grande, N.; Mazza, C.; Petrovic, R.; Testarelli, L.; Gambarini, G. Influence of size and taper of artificial canals on the trajectory of NiTi instruments in cyclic fatigue studies. Oral Surg. Oral Med. Oral Pathol. Oral Radiol. Endod. 2010, 109, 60-66. [CrossRef] 